\title{
DESCRIPTIVE STUDY OF GESTATIONAL DIABETES MELLITUS AND ITS OUTCOME IN A CENTRAL INDIAN HOSPITAL
}

\author{
Sarika Thakare ${ }^{1}$, Sachin Wankhede ${ }^{2}$
}

${ }^{1}$ Assistant Professor, Department of Obstetrics and Gynaecology, Indira Gandhi Government Medical College, Nagpur. ${ }^{2}$ Associate Professor, Department of Obstetrics and Gynaecology, Indira Gandhi Government Medical College, Nagpur.

\section{ABSTRACT}

\section{BACKGROUND}

Gestational diabetes mellitus is one of the common complications of pregnancy. It has implications for both mother and the baby. Untreated GDM leads to increased perinatal morbidity and mortality. For the mother, GDM is a very strong risk factor for the development of permanent diabetes in later life. Hence, identification of risk factors and early diagnosis with proper institution of treatment is of paramount importance.

Aim- The aim of this study was to study the pregnancy outcome in diagnosed cases of gestational diabetes mellitus.

Design- This is a descriptive study.

\section{MATERIALS AND METHODS}

This was a descriptive study conducted over a period of 2 years in a tertiary care hospital in central India; 90 study subjects were included. All cases were clinically assessed and investigated according to severity of GDM. Appropriate treatment was instituted and they were followed till term. Labour was monitored and the outcome of pregnancy was noted. All data collected was analy sed. Results were expressed as numbers and percentages.

\section{RESULTS}

The highest incidence of GDM was seen in primigravidas $42.22 \%$ and the mean age was $26.5 \%$; $10 \%$ cases had history of GDM in previous pregnancy and $14.4 \%$ had a family history of diabetes. Insulin in addition to diet control was required in $58.8 \%$ cases. Macrosomia was seen in $4.5 \%$. Incidence of IUD was $2.7 \%$, whereas $3.6 \%$ study subjects gave birth to congenitally anomalous babies. Incidence of caesarean section was $48.9 \%$ and that of PIH was 13 .

\section{CONCLUSION}

Universal screening rather than screening only those patients having risk factors of GDM should be the norm, as GDM mothers and their babies are at increased risk of unfavourable maternal and foetal outcome. Timely diagnosis and effective glycaemic control by instituting appropriate treatment can decrease if not prevent the maternal and foetal complications to a large extent.

\section{KEYWORDS}

GDM, Pregnancy, Outcome, Incidence.

HOW TO CITE THIS ARTICLE: Thakare S, Wankhede S. Descriptive study of gestational diabetes mellitus and its outcome in a central Indian hospital. J. Evolution Med. Dent. Sci. 2017;6(76):5419-5421, DOI: 10.14260/Jemds/2017/1175
BACKGROUND
GDM is defined as a carbohydrate intolerance of variable severity with onset or first recognition during pregnancy. Placental hormones and increased fat deposits mediate insulin resistance during pregnancy, thereby blocking insulin action to bind to its receptors. It usually resolves after pregnancy. The presence of GDM has implications for both mother and the baby. Some studies have indicated increased rate of perinatal mortality in untreated GDM.
In considering longer term outcomes for the baby, evidence is gradually mounting that GDM adds an intrauterine environmental risk to an already increased genetic risk for the development of obesity and/or diabetes.
For the mother, GDM is a very strong risk factor for the development of diabetes later in life. This study aims at diagnosing GDM as early as possible and institute appropriate therapy, so as to have a favourable outcome for both mother and baby.

Although, the risks associated with GDM are well recognised, the impact on the health outcomes of mother and baby is not that clear. GDM is a condition that can be effectively controlled, thereby decreasing the associated risks and eventually leading to less or no complications in mother and delivery of healthy babies.

Financial or Other, Competing Interest: None.

Submission 14-08-2017, Peer Review 07-09-2017,

Acceptance 13-09-2017, Published 21-09-2017.

Corresponding Author:

Dr. Sachin Wankhede,

\#55, Borgaon Hill,

Fago Layout,

Behind Dinshaw Factory,

Nagpur.

E-mail: drsachinwankhede@yahoo.co.in

DOI: $10.14260 /$ jemds $/ 2017 / 1175$

\section{MATERIALS AND METHODS}

This is a descriptive study, carried out in the Department of Obstetrics and Gynaecology at a Central Indian Hospital over a period of 2 years. This is a study of cases of GDM in relation to pregnancy and its outcome. All patients attending ANC OPD and subsequently diagnosed as GDM (subjects were given $75 \mathrm{~g}$ of glucose. Venous plasma glucose was measured after two hours and cases with value of $140 \mathrm{mg} / \mathrm{dL}$ or more were labelled as GDM) entered the study after obtaining informed written consent. Study cases were treated with either diet alone or with insulin therapy in addition. They were monitored with blood and urine sugar. They were followed till parturition. Various complications during the course of pregnancy were identified and treated. Labour was monitored and the outcome of pregnancy was noted. In 
indicated cases, caesarean section was done. The findings were recorded and all data collected was tabulated and analysed. Results were expressed as number and percentages.

\section{RESULTS}

\begin{tabular}{|c|c|c|}
\hline Age (In Years) & Number & Percentage \\
\hline Less than 21 & 6 & 6.67 \\
\hline $21-25$ & 41 & 45.56 \\
\hline $26-30$ & 28 & 31.11 \\
\hline $31-35$ & 11 & 12.22 \\
\hline More than 35 & 4 & 4.44 \\
\hline Total & 90 & 100 \\
\hline
\end{tabular}

Out of 90 study subjects, majority were between $21-25$ years. Minimum numbers were in the age group of more than 35 years.

\begin{tabular}{|c|c|c|}
\hline Gravida & Number & Percentage \\
\hline Primi & 38 & 42.22 \\
\hline G2 & 31 & 34.44 \\
\hline G3 & 15 & 16.67 \\
\hline G4 and above & 6 & 6.67 \\
\hline \multicolumn{2}{|c|}{ Table 2. Distribution of Study Subjects } \\
according to their Obstetric History
\end{tabular}

Out of 90 study subjects, maximum $42.22 \%$ were primigravida and $34.44 \%$ were second gravida. Only $6.67 \%$ cases were fourth gravid and above.

\begin{tabular}{|c|c|c|}
\hline Risk Factors & Number & Percentage \\
\hline Age more than 25 years & 36 & 40 \\
\hline Family history of diabetes & 13 & 14.4 \\
\hline GDM in previous pregnancy & 9 & 10 \\
\hline BMI more than 25 & 41 & 45.5 \\
\hline Pregnancy loss & 5 & 4.5 \\
\hline \multicolumn{2}{|c|}{ Table 3. Distribution of Study } \\
Subjects according to the Risk Status \\
\hline
\end{tabular}

BMI more than 25 and age more than 25 years were the primary risk factors associated with GDM.

\begin{tabular}{|c|c|c|}
\hline Outcome & Number & Percentage \\
\hline Vaginal delivery & 46 & 51.1 \\
\hline Caesarean section & 44 & 48.9 \\
\hline Congenital Anomaly & 4 & 3.6 \\
\hline Preterm delivery & 15 & 16.6 \\
\hline Macrosomia & 5 & 4.5 \\
\hline IUD & 3 & 2.7 \\
\hline PIH & 13 & 13.6 \\
\hline \multicolumn{2}{|c|}{ Table 4. Distribution of Study Subjects } \\
according to the Outcome of Pregnancy \\
\hline
\end{tabular}

The study subjects requiring insulin in addition to diet control is $53(58.8 \%)$.

\section{DISCUSSION}

Gestational diabetes is one of the common condition affecting pregnancy. The prevalence of gestational diabetes is going northwards globally. Sedentary lifestyle in urban population is one of the most important contributory factor to increasing incidence of gestational diabetes. Data collected from this study was analysed.

Table 1 shows distribution of study subjects according to the age. In the present study, maximum of $45.56 \%$ were in the age group of 21-25 years. Similarly, Seshiah $V$ et al indicated that age less than or 25 years as a risk factor for gestational diabetes. ${ }^{1}$ Least cases $4.44 \%$ were in the age group of more than 35 years, the youngest being 18 years and the oldest being 39 years. Enid Leikin et al reported a higher incidence of $7.39 \%$ cases who were more than 35 years. ${ }^{2}$ In our study, the mean age of the subjects was 26.52 years. However, E. Nordlander reported mean age of 31 years. $^{3}$ This may be because of late marriages in western countries. Several studies in the past have stated that gestational diabetes is seen in with higher frequency in women beyond the age of 25. This may be as a result of increased incidence of hypertension in pregnant women, dyslipidaemia and increased BMI which are age related metabolic changes.

Table 2 shows distribution of study subjects according to their obstetric history. In the present study, none of the study subjects had parity more than 4. However, Enid Leikin reported $4.54 \%$ cases who were more than para $4 .{ }^{2}$ This may be because these cases had previous perinatal death, unexplained stillbirth or congenital malformations not compatible with life. Highest incidence of GDM was noted in primigravidas $42.22 \%$.

Table 3 shows distribution of study subjects according to the presence of risk factors for GDM. We, in our study found that age more than 25 years, BMI more than 25, family history of diabetes followed by gestational diabetes in previous pregnancy were the most important risk factors associated with GDM. Other risk factor was previous pregnancy loss. Obese and overweight individuals show hormonal imbalance of carbohydrate regulation mechanism and insulin sensitivity. BMI more than 25 was seen in $45.5 \%$ of cases which is similar to what is reported by Hadaegh $\mathrm{F}$ et $\mathrm{al}^{4}$ and Alpana Singh et al (39.1\%). ${ }^{5}$ This is the reason why non-pregnant obese women considering pregnancy should be aware of the risk of development of GDM and how it can complicate the pregnancy.

Family history of diabetes was present in $14.4 \%$ cases. It is a known fact that women with family history of diabetes have more chances of developing gestational diabetes as compared to normal women. Abdulbari Bener et al reported a somewhat higher rate of $31.7 \%$ cases of GDM with family history of diabetes. ${ }^{6}$ Family history of diabetes mellitus has been reported to be associated with higher chances of developing GDM.6-9 Several epidemiological studies have time and again identified a family history of diabetes as a primary risk factor for the development of gestational diabetes. ${ }^{10-12}$

In the study conducted by Catherine Kim MD et al, they were of the view that recurrence of gestational diabetes varies between $30 \%-80 \%$ depending upon race, ethnicity, maternal age and BMI. ${ }^{13}$ Our study reported that $10 \%$ cases had history of GDM in previous pregnancy. Similarly, Alpana Singh et al quoted that $13 \%$ cases had history of GDM in previous pregnancy. 5

Table 4 shows distribution of study subjects according to outcome of pregnancy. Our study reported a higher rate of caesarean section (48.9\%). This may be because of higher 
incidence of PIH (13.6\%), pre-eclampsia, APH, preterm labour (16.6\%), macrosomia (4.5\%) and PROM (13.5\%). Similar results have been found by different studies that PIH $(17.9 \%)$ and rates of caesarean section $(17.1 \%)$ were higher in women with GDM.14-15 Another study in China also indicated similar rate of complications in GDM mothers. Increased rates of caesarean section may also be due to increased rate of foetal distress in GDM mothers. Macrosomia also contributes to higher rate of caesarean section.

Neonates born to GDM mothers are at increased risk of macrosomia, hyperbilirubinaemia, hypoglycaemia, birth injuries and other complications. Our study reported macrosomia (4.5\%) and preterm births (16.6\%). Other complications like jaundice and hypoglycaemia were also found. A study by Hong et al found that infants born to gestational diabetes mothers are more likely to be born preterm $(10.7 \%)$ or have macrosomia (4.3\%). Our study reported IUD in 3 cases. Uncontrolled Diabetes can produce sudden unexplained IUD. The aim of early diagnosis and prompt management of GDM during pregnancy by insulin therapy is to prevent neonatal perinatal complications, macrosomia and IUD. Our study reported congenital anomalies in $3.6 \%$ cases. Several studies have come to the conclusion that mothers with pre-existing but undiagnosed type 2 diabetes are at a higher risk of having congenitally malformed babies. A study conducted on diabetic women in United Kingdom showed a four-fold increase in congenital malformations than general population. ${ }^{16}$ Proper counselling prior to conception and proper control of glycaemia in preconception period can reduce the incidence of congenital anomalies.

A need is felt in terms of more research in the field of interventions directed at reducing weight and thereby reducing the impact obesity has on complications of pregnancy, as it is the single most modifiable risk factor frequently associated with gestational diabetes. Education and awareness will also play a vital role in it. Timely diagnosis and effective glycaemic control by instituting appropriate treatment can decrease if not prevented the maternal and foetal complications to a large extent.

\section{CONCLUSION}

Universal screening rather than screening only those patients having risk factors of GDM should be the norm, as GDM mothers and their babies are at increased risk of unfavourable maternal and foetal outcome. The adverse outcomes of pregnancy can be greatly reduced by doctors by increasing awareness about the risk factors and at the same time instituting standard treatment inclusive of lifestyle management and dietary control.

\section{REFERENCES}

[1] Seshiah V, Balaji V, Balaji MS, et al. Prevalence of gestational diabetes mellitus in South India-a community based study. J Assoc Physicians India 2008;56:329-33.
[2] Leikin EL, Jenkins JH, Pomerantz GA, et al. Abnormal glucose screening tests in pregnancy: a risk factor for fetal macrosomia. Obstet Gynecol 1987;69(4):570-3.

[3] Nordlander E, Hanson U, Persson B. Factors influencing neonatal morbidity in gestational diabetic pregnancy. British Journal of Obstetrics and Gynecology 1989;96(6):671-8.

[4] Hadaegh F, Tohidi M, Harati $\mathrm{H}$, et al. Prevalence of gestational diabetes mellitus in southern Iran. Endocr Pract 2005;11(5):313-8.

[5] Singh A, Uma B. Incidence of gestational diabetes mellitus and its outcomes in a rural population. Journal of Evolution of Medical and Dental Sciences 2013;2(13):1982-6.

[6] Bener A, Saleh NM, Al-Hamaq A. Prevalence of gestational diabetes and associated maternal and neonatal complications in a fast-developing community: global comparisons. International Journal of Women`s Health 2011;3:367-73.

[7] Zargar AH, Sheikh MI, Bashir MI, et al. Prevalence of gestational diabetes mellitus in Kashmiri women from the Indian subcontinent. Diabetes Res Clin Pract 2004;66(2):139-45.

[8] Wagaarachi PT, Fernando L, Premchadra P, et al. Screening based on risk factors for gestational diabetes in an Asian population. J Obstet Gynecol 2001;21(1):32-4.

[9] Garshasbi A, Faghihzadeh S, Naghizadeh MM, et al. Prevalence and risk factors for gestational diabetes mellitus in Tehran. J Family Reprod Health 2002;2:7580.

[10] Ben-Haroush A, Yogev Y, Hod M. Epidemiology of GDM and its association with type 2 diabetes. Diabet Med 2004;21(2):103-13.

[11] Teh WT, Teede HJ, Paul E, et al. Risk factors for gestational diabetes mellitus: implications for the application of screening guidelines. Aust N Z J Obstet Gyneacol 2011;51(1):26-30.

[12] Chu SY, Callaghan WM, Kim SY, et al. Maternal obesity and risk of gestational diabetes mellitus. Diabetes Care 2007;30(8):2070-6.

[13] Kim C, Berger DK, Chamany S. Recurrence of gestational diabetes mellitus: a systematic review. Diabetes Care 2007;30(5):1314-9.

[14] Hong JU, Rumbold AR, Wilson KJ, et al. Borderline gestational diabetes mellitus and pregnancy outcomes. BMC Pregnancy Childbirth 2008;8:31.

[15] Gunderson EP, Lewis CE, Tsai AL, et al. A 20 year prospective study of childbearing and incidence of diabetes in young women, controlling for glycemia before conception. Diabetes 2007;56(12):2990-6.

[16] Macintosh MM, Fleming KM, Bailey JA, et al. Perinatal mortality and congenital anamolies in babies of women with type 1 or 2 diabetes in England, Wales, and Northern Ireland: population based study. BMJ 2006;333:177. 